\title{
Resting Heart Rate and In-Hospital Mortality in Acute Ischemic Stroke Patients With and Without Atrial Fibrillation
}

\author{
Qiao Han, MD; Chunyuan Zhang, MD; Shoujiang You, MD, PhD; Danni Zheng, PhD; \\ Chongke Zhong, PhD; Hongli Dong, MD, PhD; Xianhui Wang, MD; \\ Shaofang Pei, MD; Yongjun Cao, MD, PhD; Chun-Feng Liu, MD, PhD
}

\begin{abstract}
Background: The prognostic role of resting heart rate (RHR) on mortality in acute ischemic stroke (AIS) patients including atrial fibrillation $(A F)$ is unclear. This study evaluated the relationship between RHR and in-hospital mortality among all AIS patients with and without AF.

Methods and Results: The study enrolled 3,447 AIS patients from December 2013 to May 2014 across 22 hospitals in Suzhou City. Patients were divided into 2 groups based on median baseline RHR ( $<76$ and $\geq 76$ beats $/ \mathrm{min})$. Cox proportional hazard regression models were used to estimate the effects of RHR on all-cause in-hospital mortality. During hospitalization, 124 patients (3.6\%) died from all causes. A multivariable model adjusted for potential covariates showed that higher RHR ( $\geq 76$ beats $/ \mathrm{min}$ ) was associated with an increase in the risk of in-hospital mortality among AIS patients (hazard ratio [HR] 1.63; 95\% confidence interval [Cl] 1.09-2.45; $\mathrm{P}=0.018)$. This relationship was consistent in a subgroup analysis of patients without $A F(\mathrm{HR} 2.39 ; 95 \% \mathrm{Cl} 1.29-4.45 ; \mathrm{P}=0.006)$. However, there was no significant association between higher RHR and in-hospital mortality among patients with $A F(P=0.654)$. Similar findings were confirmed in analyses with heart rate as a continuous variable.
\end{abstract}

Conclusions: Higher RHR at admission was independently associated with in-hospital mortality in AIS patients without AF.

Key Words: Acute ischemic stroke; Atrial fibrillation; In-hospital mortality; Prognosis; Resting heart rate

$\mathbf{P}$ revious epidemiological and clinical studies demonstrated that high resting heart rate is significantly associated with increased mortality in the general population, as well as in patients with coronary artery disease, heart failure, hypertension, and stroke. ${ }^{1-9}$ High resting heart rate is a risk factor for long-term (24 months) and short-term (in-hospital or 3 months) mortality after ischemic stroke, ${ }^{7-10}$ as well as hemorrhage stroke. ${ }^{11}$ However, most of these studies were restricted to patients experiencing acute ischemic stroke (AIS) or transient ischemic attack (TIA) without a history of atrial fibrillation (AF)..$^{7-11}$ $\mathrm{AF}$ is one of the most important risk factors for ischemic stroke, accounting for $10-25 \%$ of all ischemic strokes and associated with high mortality and morbidly. ${ }^{12-15}$ Among AF patients, study findings on the relationship between heart rate and mortality are conflicting. One study reported that high heart rate is associated with increased mortality in acute myocardial infarction patients with $\mathrm{AF},{ }^{16}$ whereas another study indicated a J-shaped relationship between heart rate and mortality in patients with permanent AF. ${ }^{17}$ Currently, there is a paucity of data on the prognostic role of heart rate on outcomes of ischemic stroke patients with a history of AF. The aim of this study was to evaluate the possible association between high heart rate and in-hospital mortality in AIS patients with and without AF.

\section{Study Participants}

From December 2013 to May 2014, patients with AIS or

Received November 5, 2019; revised manuscript received December 28, 2019; accepted January 15, 2020; J-STAGE Advance Publication released online February 28, 2020 Time for primary review: 15 days

Department of Neurology and Suzhou Clinical Research Center of Neurological Disease, The Second Affiliated Hospital of Soochow University, Suzhou (Q.H., C. Zhang, S.Y., Y.C., C.-F.L.); Department of Neurology, Suzhou TCM Hospital Affiliated to Nanjing University of Chinese Medicine, Suzhou (Q.H., H.D.), China; Discipline of Pharmacology, Faculty of Medicine and Health, University of Sydney, Sydney, New South Wales (D.Z.); The George Institute for Global Health, Faculty of Medicine, University of New South Wales, Sydney, New South Wales (D.Z.), Australia; Department of Epidemiology, School of Public Health, Medical College of Soochow University, Suzhou (C. Zhong); Department of Neurology, Taicang First People's Hospital, Suzhou (X.W.); Department of Neurology, Suzhou Hospital Affiliated to Nanjing Medical University, Suzhou (S.P.); and Institutes of Neuroscience, Soochow University, Suzhou (Y.C., C.-F.L.), China

The first three authors are equal first authors (Q.H., C. Zhang, S.Y.).

Mailing address: Yongjun Cao, MD, PhD, Department of Neurology, The Second Affiliated Hospital of Soochow University, No. 1055, Sanxiang Road, 215004 Suzhou, Jiangsu, China. E-mail: yongjuncao@126.com or Chun-Feng Liu, MD, PhD, Department of Neurology, The Second Affiliated Hospital of Soochow University, No. 1055, Sanxiang Road, 215004 Suzhou, Jiangsu, China. E-mail: liuchunfeng@suda.edu.cn

ISSN-1346-9843 All rights are reserved to the Japanese Circulation Society. For permissions, please e-mail: cj@j-circ.or.jp 
TIA were recruited from 22 hospitals in Suzhou, China. Patients aged $\geq 18$ years with a clinical diagnosis of AIS or TIA were considered eligible for the study. A diagnosis of ischemic stroke was made according to World Health Organization-defined criteria based on patient history, clinical data, and neuroimaging results (computed tomography or magnetic resonance imaging). A team of investigators, including neurologists, reviewed the eligibility of study participants. Exclusion criteria were a diagnosis of TIA and time from onset to admission $>7$ days. In all, 3,450 patients were potentially eligible for inclusion in the present study. Of these, 3 patients were excluded because of lack of heart rate data on admission. A flowchart of participant selection is shown in Figure 1.

\section{Ethics Statement}

This study was approved by the Ethics Committee of The Second Affiliated Hospital of Soochow University, as well as ethics committees at the participating hospitals. Written consent was obtained from all study participants or their immediate family members.

\section{Data Collection and Outcome Assessment}

Baseline information was collected, including patient demographics, vascular risk factors, stroke severity (National Institutes of Health Stroke Scale [NIHSS] score and modified Rankin Scale score), medication use, imaging data, and diagnosis-related information. Vascular risk factors included a history of stroke, hypertension, diabetes mellitus, AF, or coronary artery disease, current or previous smoking status, and alcohol consumption. Information on these factors was obtained by interviews with patients or their family members (if patients were not able to communicate). Current smoking was defined as having smoked at least 1 cigarette per day for 1 year or more. Data on the amount and type of alcohol consumed during the past year were collected. Alcohol consumption was defined as having consumed at least 1 alcoholic drink per day during the past year. Hypertension was defined as having a systolic blood pressure (BP) $\geq 140 \mathrm{mmHg}$ and/or diastolic BP $\geq 90 \mathrm{mmHg}$ or the use of antihypertensive medications. Diabetes mellitus was defined as having fasting glucose $\geq 7.0 \mathrm{mmol} / \mathrm{L}(126 \mathrm{mg} / \mathrm{dL})$, non-fasting glucose $\geq 11.1 \mathrm{mmol} / \mathrm{L}(200 \mathrm{mg} / \mathrm{dL})$ with classic symptoms of hyperglycemia or hyperglycemic crisis or the use of glucoselowering drugs. AF was defined as having a history of $\mathrm{AF}$, confirmed by $\geq 1$ electrocardiogram (ECG) or the presence of arrhythmia during hospitalization. Blood samples were collected within $24 \mathrm{~h}$ of hospital admission. Laboratory variables were assayed at local laboratories. Participants' resting heart rate was recorded from a 12-lead ECG or electrocardiographic monitoring, which was conducted at the time of hospital admission by a nurse with the patient lying in a supine position. The primary endpoint for the present study was all-cause in-hospital mortality.

\section{Statistical Analysis}

For the main analysis, resting heart rate was assessed as a dichotomous variable, divided according to median heart rate ( $<76$ and $\geq 76$ beats $/ \mathrm{min})$. Continuous variables are expressed as the mean \pm SD or median value with interquartile range (IQR) and were compared using independent Student's t-test or the Wilcoxon rank-sum test. Categorical variables are expressed as frequencies and percentages and were compared using the Chi-squared test.

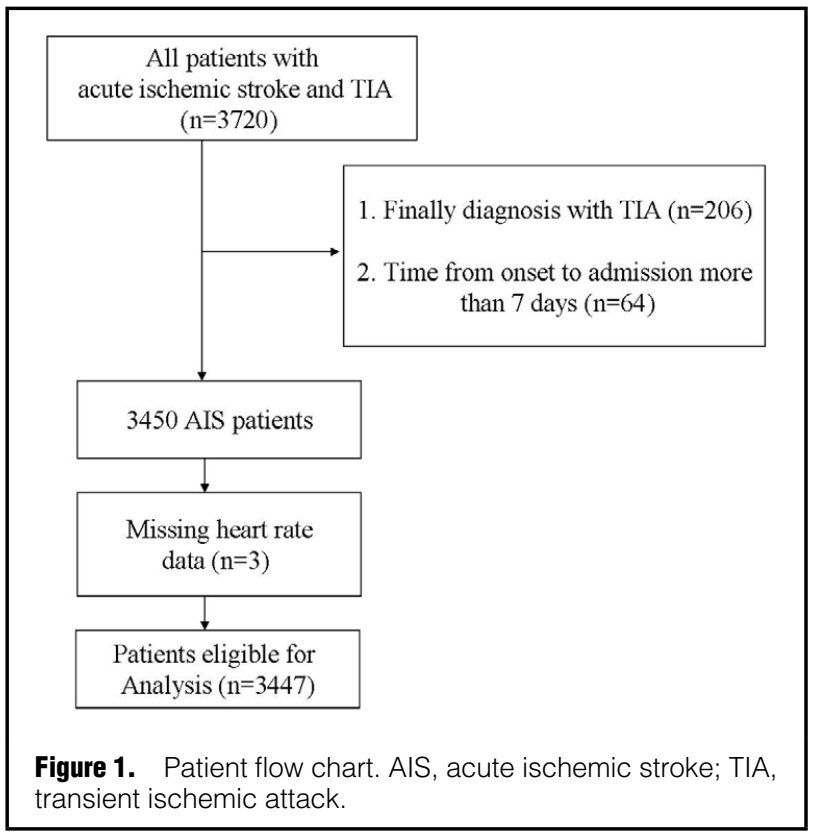

The cumulative risk of all-cause mortality among the 2 groups was estimated using Kaplan-Meier curves and compared by the log-rank test. Cox proportional hazards regression models were used to evaluate associations between heart rate and all-cause in-hospital mortality. Hazard ratios (HRs) and 95\% confidence intervals (CIs) of death were calculated for heart rate $\geq 76$ beats/min with heart rate $<76$ beats/min as the reference, adjusted for important confounding factors including age, sex, systolic $\mathrm{BP}$, time from onset to admission, cigarette smoking status, alcohol drinking, history of hypertension, history of diabetes mellitus, history of AF, history of stroke, antihypertensive medication, estimated glomerular filtration rate, body temperature, stroke subtype (stroke syndromes), thrombolysis treatment, and baseline NIHSS score ( $<4$ vs. $\geq 4)$. To assess the robustness of the association between baseline heart rate and in-hospital mortality, we assessed baseline heart rate as a continuous variable (by 10-beats/min increases) for sensitivity analyses. We further evaluated the potential role of AF on the relationship between heart rate and in-hospital mortality using interaction terms; the heterogeneity between subgroups was estimated by adding an interaction term to the model. All P-values are 2-tailed, and significance was set at $\mathrm{P}<0.05$. All analyses were conducted using SPSS Version 17.0 (SPSS Inc., Chicago, IL, USA).

\section{Results}

There were 3,450 AIS patients who met the diagnosis criteria in the present study, of whom $3(0.08 \%)$ were excluded due to missing heart rate data. Complete data on conventional risk factors and heart rate at admission were available for 3,447 patients. The mean $( \pm \mathrm{SD})$ patient age was $68.6 \pm 12.9$ years, and the median baseline NIHSS score was 4.0 (IQR 2.0-7.0). Compared with participants with a lower heart rate $(<76$ beats/min), those with higher heart rate ( $\geq 76$ beats $/ \mathrm{min}$ ) were more likely to be female, have higher systolic and diastolic BP, higher blood glucose, and more severe stroke (as indicated by higher NIHSS scores), 


\begin{tabular}{|c|c|c|c|}
\hline & \multicolumn{2}{|c|}{ Resting heart rate at baseline (beats/min) } & \multirow{2}{*}{ P-value } \\
\hline & $<76$ & $\geq 76$ & \\
\hline No. subjects & 1,699 & 1,748 & \\
\hline \multicolumn{4}{|l|}{ Demographics } \\
\hline Age (years) & $68.6 \pm 12.4$ & $68.5 \pm 13.3$ & 0.881 \\
\hline Male sex & $1,017(59.9)$ & $974(55.7)$ & 0.014 \\
\hline Cigarette smoking & $387(22.8)$ & $302(17.3)$ & $<0.001$ \\
\hline Alcohol consumption & $196(11.5)$ & $142(8.1)$ & 0.001 \\
\hline \multicolumn{4}{|l|}{ Clinical features } \\
\hline Time from onset to hospital (h) & $24.0[6.0-72.0]$ & $24.0[5.0-48.0]$ & 0.005 \\
\hline Hospital stay (days) & $10.0[8.0-14.0]$ & $11.0[8.0-14.0]$ & 0.256 \\
\hline Systolic BP (mmHg) & $151.1 \pm 22.7$ & $153.8 \pm 22.8$ & 0.001 \\
\hline Diastolic BP $(\mathrm{mmHg})$ & $83.8 \pm 12.8$ & $87.2 \pm 13.6$ & $<0.001$ \\
\hline Resting heart rate (beats/min) & $67.5 \pm 5.9$ & $85.9 \pm 11.3$ & $<0.001$ \\
\hline $\mathrm{TG}(\mathrm{mmol} / \mathrm{L})$ & $1.2[0.9-1.7]$ & $1.2[0.8-1.7]$ & 0.229 \\
\hline TC (mmol/L) & $4.6[3.9-5.3]$ & $4.5[3.9-5.3]$ & 0.822 \\
\hline LDL-C (mmol/L) & $2.7[2.1-3.3]$ & $2.7[2.1-3.3]$ & 0.743 \\
\hline HDL-C (mmol/L) & $1.2[1.0-1.4]$ & $1.2[1.0-1.4]$ & 0.366 \\
\hline $\mathrm{FPG}(\mathrm{mmol} / \mathrm{L})$ & $5.9[5.0-6.8]$ & $5.9[5.1-7.5]$ & $<0.001$ \\
\hline Body temperature $\left({ }^{\circ} \mathrm{C}\right)$ & $36.5[36.2-36.7]$ & $36.5[36.2-36.8]$ & 0.031 \\
\hline eGFR (mL/min/1.73 m²) & $98.1 \pm 32.1$ & $98.0 \pm 36.3$ & 0.925 \\
\hline NIHSS score & $3.0[2.0-6.0]$ & $4.0[2.0-8.0]$ & $<0.001$ \\
\hline \multicolumn{4}{|l|}{ Medical history } \\
\hline Hypertension & 1,323 (77.9) & $1,377(78.8)$ & 0.518 \\
\hline Diabetes mellitus & $416(24.5)$ & $476(27.2)$ & 0.066 \\
\hline Coronary artery disease & $89(5.2)$ & $104(5.9)$ & 0.364 \\
\hline $\mathrm{AF}$ & $221(13.0)$ & $311(17.8)$ & $<0.001$ \\
\hline Stroke & 377 (22.2) & $395(22.6)$ & 0.774 \\
\hline \multicolumn{4}{|l|}{ Medication history } \\
\hline Antihypertensive therapy & $986(58.0)$ & $1,028(58.8)$ & 0.644 \\
\hline Antiplatelet therapy & $121(7.1)$ & $131(7.5)$ & 0.675 \\
\hline Anticoagulation therapy & $19(1.1)$ & $18(1.0)$ & 0.801 \\
\hline Antiglycemic therapy & $306(18.0)$ & $343(19.6)$ & 0.226 \\
\hline Statin therapy & $49(2.9)$ & $55(3.1)$ & 0.653 \\
\hline Thrombolysis treatment & $36(2.1)$ & $49(2.8)$ & 0.195 \\
\hline Stroke syndrome (OCSP classification) & & & 0.001 \\
\hline TACS & $139(8.2)$ & $203(11.6)$ & \\
\hline PACS & $835(49.1)$ & $892(51.0)$ & \\
\hline POCS & $422(24.8)$ & $383(21.9)$ & \\
\hline LACS & $303(17.8)$ & $270(15.4)$ & \\
\hline
\end{tabular}

Continuous variables are expressed as the mean \pm SD or as the median [interquartile range]. Categorical variables are expressed as $\mathrm{n}(\%)$. AF, atrial fibrillation; BP, blood pressure; eGFR, estimated glomerular filtration rate; FPG, fasting plasma glucose; HDL-C, high-density lipoprotein cholesterol; LACS, lacunar syndrome; LDL-C, low-density lipoprotein cholesterol; mRS, modified Rankin Scale; NIHSS, National Institutes of Health Stroke Scale; OCSP, Oxfordshire Community Stroke Project; PACS, partial anterior circulation syndrome; POCS, posterior circulation syndrome; TACS, total anterior circulation syndrome; TC, total cholesterol; TG, triglycerides.

and tended to have lower rates of smoking and alcohol consumption, higher rates of a history of $\mathrm{AF}$, and a shorter time from onset to hospital (Table 1).

During hospitalization, 124 patients $(3.6 \%)$ died from any cause. The cumulative incidence rates of all-cause mortality for patients with higher and lower heart rate $(<76$ and $\geq 76$ beats $/ \mathrm{min}$ ) were $4.9 \%$ and $2.2 \%$, respectively. Figure 2 presents the Kaplan-Meier curves for the cumulative incidence rate of all-cause mortality by heart rate status (log-rank $\mathrm{P}<0.001)$. In the unadjusted Cox model, in-hospital mortality was significantly increased among study participants with a higher $(\geq 76$ beats $/ \mathrm{min})$ than lower (<76 beats/min) heart rate (HR 2.18; 95\% CI 1.49-3.19;
$\mathrm{P}<0.001)$. After adjusting for age, sex, time from onset to admission, baseline NIHSS score ( $<4$ vs. $\geq 4$ ), stroke subtype, and other traditional risk factors, the mortality HR for patients with a higher heart rate at admission was 1.63 (95\% CI 1.09-2.45; $\mathrm{P}=0.018$ ) (Table 2). The association between heart rate and in-hospital mortality remained significant (adjusted HR 1.13; 95\% CI 1.02-1.24; $\mathrm{P}=0.014$, for every 10 -beats/min increase) with resting heart rate as a continuous variable (Table 2).

There was heterogeneity in the effect of heart rate on in-hospital mortality by AF status (unadjusted Pinteraction= 0.041; adjusted Pinteraction $=0.040$ ), indicating that the effect of heart rate on in-hospital mortality differed according to 
a patient's AF status. Therefore, multivariate models were built to separately assess the effects of heart rate in patients with and without AF separately (Table 3).

There were 2,915 patients without AF and 532 patients with AF. Of the patients without AF, $58(2.0 \%)$ died from all causes, compared with 66 patients with AF (12.4\%). Figure 3 presents the Kaplan-Meier curves for the cumulative incidence of all-cause mortality by heart rate group in patients with (log-rank $\mathrm{P}=0.302$; Figure 3B) and without $(\log$-rank $\mathrm{P}<0.001$; Figure $3 \mathrm{~A}) \mathrm{AF}$. After adjusting for traditional risk factors, compared with lower heart rate ( $<76$ beats $/ \mathrm{min}$ ) at admission, the HR for mortality for patients with a higher heart rate $(\geq 76$ beats $/ \mathrm{min})$ at admission was $2.39(95 \%$ CI $1.29-4.45 ; \mathrm{P}=0.006$; Table 3) in patients without AF. However, there was no significant association between heart rate and in-hospital mortality in patients with $\mathrm{AF}$ after adjusting for potential confounders (HR 1.13; 95\% CI 0.65-1.97; P=0.654). The heterogeneous effect of heart rate on in-hospital mortality in patients with or without AF was also confirmed in analyses with heart rate as a continuous variable (Table 3 ).

\section{Discussion}

The present study of 3,447 patients investigated the relationship between resting heart rate on admission and the in-hospital mortality in AIS patients. We found that a higher resting heart rate at admission is associated with 1.63 -fold increased risk of in-hospital mortality in AIS patients. In addition, the prognostic effect of resting heart rate appeared to differ in ischemic stroke patients by $\mathrm{AF}$ status. In patients without AF, there was 2.39-fold increased in-hospital mortality in patients with a heart rate $\geq 76$ beats/min compared with patients with a heart rate $<76$ beats/min. However, no independent relationship between heart rate and in-hospital mortality was observed in AIS patients with AF. Similar findings were confirmed in sensitivity analyses with heart rate as a continuous variable.

A growing body of evidence suggests that having higher heart rate at admission is associated with increased mortality after stroke. ${ }^{7-11}$ Data from the Prevention Regimen for Effectively Avoiding Second Stroke trial (PRoFESS) of 20,165 ischemic stroke patients indicated that high heart rate is a risk indicator for all-cause or vascular mortality at 3 months. ${ }^{7}$ The Virtual International Stroke Trials Archive (VISTA) study of 5,606 AIS patients showed that higher heart rate ( $>86$ beats $/ \mathrm{min})$ is significantly linked to mortality, heart failure, and a higher degree of dependence after 90 days. ${ }^{9}$ Erdur et al also reported that high heart rate on admission is independently associated with in-hospital

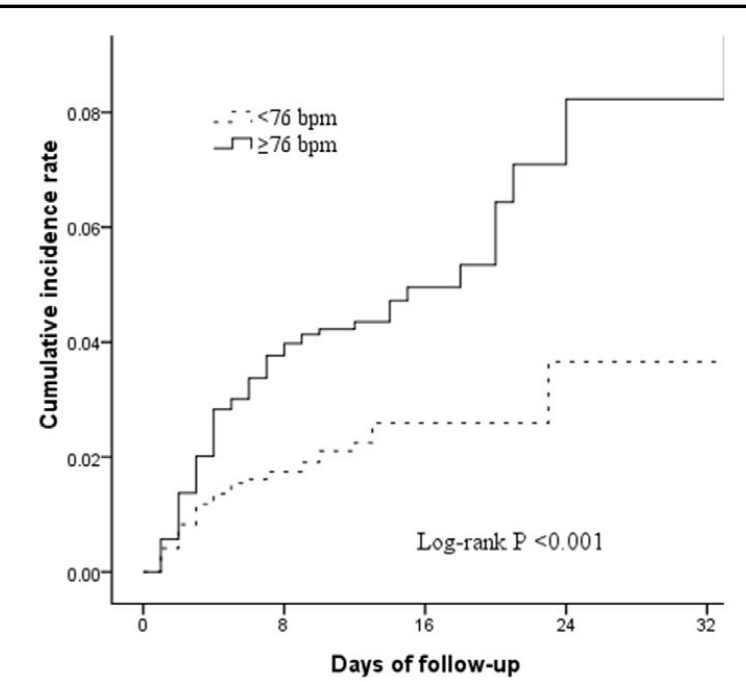

Figure 2. Cumulative incidence curves of in-hospital mortality, according to resting heart rate at admission ( $<76$ vs. $\geq 76$ beats/min).

mortality in 1,335 AIS patients. ${ }^{8}$ However, most of these studies were restricted to patients without AF. Consistent with prior studies, the present analyses of 3,447 AIS patients (including those with $\mathrm{AF}$ ) demonstrated an independent relationship between high heart rate ( $\geq 76$ beats $/ \mathrm{min})$ at admission and in-hospital mortality, after adjusting for age, sex, time from onset to admission, baseline NIHSS score, and other conventional risk factors.

In contrast with ischemic stroke patients without $\mathrm{AF}$, the relationship between heart rate and in-hospital mortality was not significant in patients with AF. These results, together with those of previous studies, ${ }^{16-18}$ could suggest that the prognostic effect of heart rate may vary in AF patients according to the types of comorbidities. Data from the OMEGA trial including 211 acute myocardial infarction patients with AF on admission indicated that a high HR ( $\geq 95$ beats/min) on admission was associated with increased risk of 1-year mortality. ${ }^{16}$ The study of Steinberg et al of 2,812 US outpatients with permanent AF demonstrated a J-shaped relationship between heart rate and mortality. ${ }^{17}$ Subgroup analysis of patients with concurrent diabetes mellitus and AF in the Action in Diabetes and Vascular Disease: Preterax and Diamicron MR Controlled Evaluation (ADVANCE) trial indicated no significant association between heart rate and all-cause mortality. ${ }^{18} \mathrm{In}$ the present study, the rate of in-hospital mortality of $12.4 \%$

\begin{tabular}{|c|c|c|c|c|c|c|c|}
\hline & \multirow{2}{*}{$\begin{array}{l}\text { No. cases } \\
(\%)\end{array}$} & \multicolumn{2}{|c|}{ Unadjusted } & \multicolumn{2}{|c|}{ Model 1} & \multicolumn{2}{|l|}{ Model 2} \\
\hline & & HR (95\% Cl) & P-value & HR (95\% Cl) & P-value & HR $(95 \% \mathrm{Cl})$ & P-value \\
\hline \multicolumn{8}{|l|}{ Heart rate (beats/min) } \\
\hline$<76$ & $38 / 1,699(2.2)$ & 1.00 (Ref.) & & 1.00 (Ref.) & & 1.00 (Ref.) & \\
\hline$\geq 76$ & $86 / 1,748(4.9)$ & $2.18(1.49-3.19)$ & $<0.001$ & $2.10(1.43-3.08)$ & $<0.001$ & $1.63(1.09-2.45)$ & 0.018 \\
\hline Per 10-beats/min increase & & $1.42(1.30-1.55)$ & $<0.001$ & $1.37(1.26-1.50)$ & $<0.001$ & $1.13(1.02-1.24)$ & 0.014 \\
\hline
\end{tabular}

Model 1, adjusted for age and sex. Model 2, adjusted for age, sex, systolic BP, time from onset to admission, cigarette smoking status, alcohol drinking, history of hypertension, history of diabetes mellitus, history of AF, history of stroke, eGFR, body temperature, antihypertensive medication, stroke syndrome, thrombolysis treatment, and baseline NIHSS score (<4 vs. $\geq 4)$. Cl, confidence interval; HR, hazard ratio. Other abbreviations as in Table 1. 
Table 3. Associations Between Resting Heart Rate and In-Hospital All-Cause Mortality in Ischemic Stroke Patients With and Without Atrial Fibrillation

\begin{tabular}{|c|c|c|c|c|c|c|c|}
\hline & \multirow{2}{*}{$\begin{array}{l}\text { No. cases } \\
(\%)\end{array}$} & \multicolumn{2}{|c|}{ Unadjusted } & \multicolumn{2}{|c|}{ Model 1} & \multicolumn{2}{|l|}{ Model 2} \\
\hline & & HR $(95 \% \mathrm{Cl})$ & P-value & HR (95\% Cl) & P-value & HR $(95 \% \mathrm{Cl})$ & P-value \\
\hline Without AF & & & $0.041^{\mathrm{a}}$ & & $0.029^{a}$ & & $0.040^{\mathrm{a}}$ \\
\hline \multicolumn{8}{|c|}{ Resting heart rate at baseline (beats/min) } \\
\hline$<76$ & $15 / 1,478(1.0)$ & 1.00 (Ref.) & & 1.00 (Ref.) & & 1.00 (Ref.) & \\
\hline$\geq 76$ & $43 / 1,437(3.0)$ & $2.95(1.64-5.32)$ & $<0.001$ & $2.97(1.65-5.35)$ & $<0.001$ & $2.39(1.29-4.45)$ & 0.006 \\
\hline $\begin{array}{l}\text { Per 10-beats/min } \\
\text { increase }\end{array}$ & & $1.61(1.41-1.84)$ & $<0.001$ & $1.55(1.36-1.77)$ & $<0.001$ & $1.20(1.03-1.38)$ & 0.018 \\
\hline \multicolumn{8}{|l|}{ With AF } \\
\hline \multicolumn{8}{|c|}{ Resting heart rate at baseline (beats/min) } \\
\hline$<76$ & 23/221 (10.4) & 1.00 (Ref.) & & 1.00 (Ref.) & & 1.00 (Ref.) & \\
\hline$\geq 76$ & $43 / 311(13.8)$ & $1.30(0.79-2.16)$ & 0.307 & $1.26(0.76-2.10)$ & 0.365 & $1.13(0.65-1.97)$ & 0.654 \\
\hline $\begin{array}{l}\text { Per 10-beats } / \mathrm{min} \\
\text { increase }\end{array}$ & & $1.14(1.01-1.29)$ & 0.032 & $1.14(1.00-1.29)$ & 0.036 & $1.07(0.94-1.21)$ & 0.326 \\
\hline
\end{tabular}

Model 1, adjusted for age and sex. Model 2, adjusted for age, sex, systolic BP, time from onset to admission, cigarette smoking status, alcohol drinking, history of hypertension, history of diabetes mellitus, history of stroke, eGFR, body temperature, antihypertensive medication, stroke syndrome, thrombolysis treatment, and baseline NIHSS score (<4 vs. $\geq 4)$. aP-value for interaction between AF and heart rate. Abbreviations as in Tables 1,2.
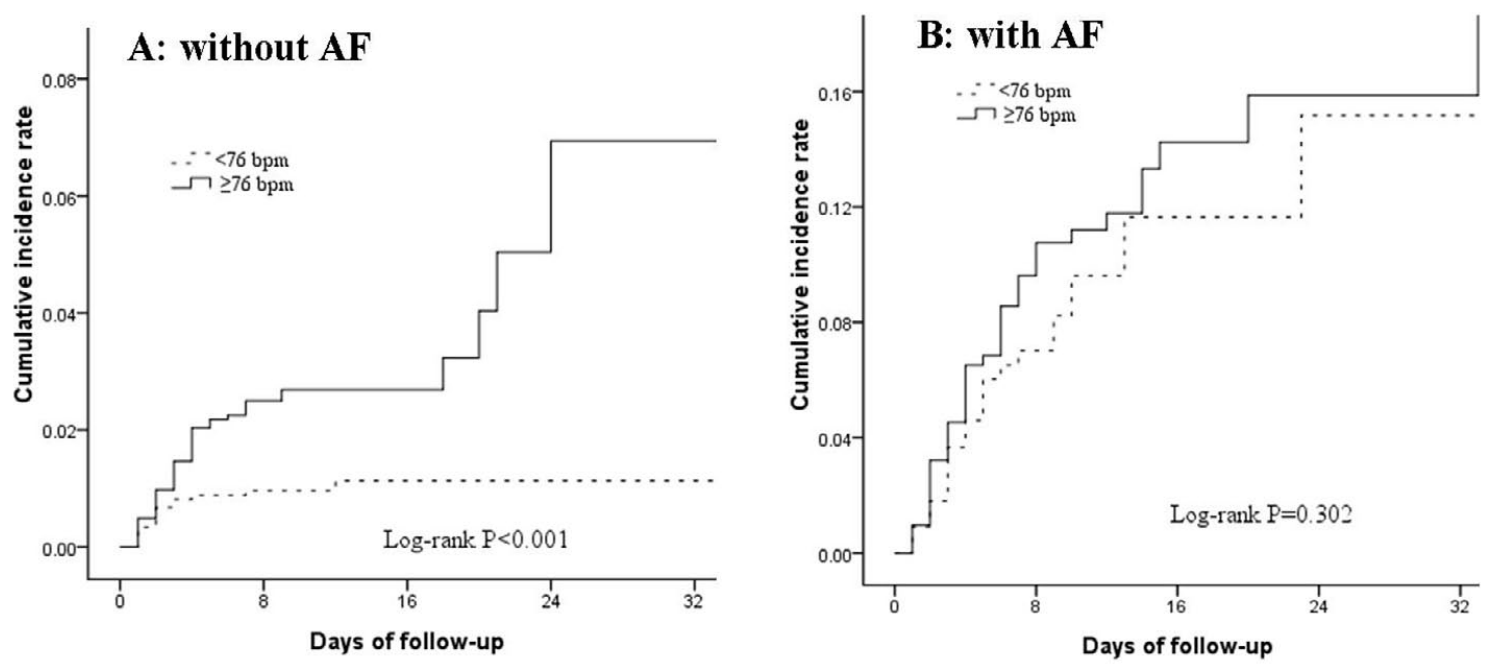

Figure 3. Cumulative incidence curves of in-hospital mortality according to resting heart rate at admission ( $<76$ vs. $\geq 76$ beats/min) in patients $(\mathbf{A})$ without and $(\mathbf{B})$ with atrial fibrillation (AF).

in AF patients was markedly higher than that of patients without AF (2.0\%). The AF patients were more likely be older ${ }^{19,20}$ and have increased stroke severity, ${ }^{14,19}$ which are factors leading to increased rates of mortality in both heart rate groups. The Rate Control Efficacy in Permanent Atrial Fibrillation: a Comparison between Lenient versus Strict Rate Control II (RACE II) trial showed that strict heart rate control ( $<80$ beats/min) did not decrease the mortality risk in patients with permanent $\mathrm{AF},{ }^{21}$ and this may be another possible reason for the observed lack of effect of high heart rate on mortality rates in patients with AF.

Several mechanisms possibly explain the association between high heart rate and increased risk of in-hospital mortality in patients without AF. First, high heart rate may reflect sympathetic nervous overactivity. Sympathetic nervous overactivity was associated with high night-time blood pressure ${ }^{22}$ and inflammatory response, ${ }^{23}$ which are known predictors of mortality in stroke. ${ }^{\mathbf{2 2 , 2 4 , 2 5}}$ Second, blood glucose is higher in patients with a high heart rate, and this is significantly associated with mortality and poor outcome. ${ }^{26,27}$

A strength of this study it the relatively large, wellcharacterized patient population. To the best of our knowledge, the present study is the first to investigate the prognostic effect of heart rate in ischemic stroke patients with and without AF. However, there are still some potential limitations that merit consideration. First, this cohort included some patients whose time from onset to admission exceeded $48 \mathrm{~h}$; therefore, the heart rate at admission may not accurately reflect the heart rate at stroke onset. Second, we did not have detailed information on the use of medications that could have altered the heart rate and/or rhythm at baseline (e.g., $\beta$-blockers). Third, the heart rate of some patients was derived from electrocardiograph monitoring. In addition, we did not collect post-baseline 
heart rate, heart rate variability, and prestroke disability data, which may also be associated with in-hospital mortality. Finally, we did not have information on the cause of death, which would improve our understanding of the underlying causes for the heart rate variations, although the most common reason for in-hospital mortality after AIS was the ischemic stroke itself.

\section{Conclusions}

The results of this study showed that high resting heart rate at admission was significantly associated with an increased risk of all-cause in-hospital mortality in AIS patients, particularly in those without AF. The findings suggest that high resting heart rate could be a useful marker for the prediction of in-hospital mortality and present a potential treatment target in AIS patients without AF.

\section{Acknowledgments}

The authors thank the study participants, their relatives, and the clinical staff for their support and contributions to this study.

\section{Sources of Funding}

This work was supported, in part, by grants from the National Natural Science Foundation of China (81901198), Basic Research of Suzhou Medical and Health Care (SYS201724), Suzhou Clinical Research Center of Neurological Disease (Szzx201503), Natural Science Foundation for Higher Education of Jiangsu Province of China (19KJB320004), and The Second Affiliated Hospital of Soochow University Preponderant Clinic Discipline Group Project Funding (XKQ2015002). This work was also supported, in part, by the Young Elite Scientists Sponsorship Program by China Association for Science and Technology (2018QNRC001).

\section{Conflict of Interest}

None declared.

\section{References}

1. Kolloch R, Legler UF, Champion A, Cooper-Dehoff RM, Handberg E, Zhou Q, et al. Impact of resting heart rate on outcomes in hypertensive patients with coronary artery disease: Findings from the INternational VErapamil-SR/trandolapril STudy (INVEST). Eur Heart J 2008; 29: 1327-1334.

2. Bohm M, Swedberg K, Komajda M, Borer JS, Ford I, DubostBrama A, et al. Heart rate as a risk factor in chronic heart failure (SHIFT): The association between heart rate and outcomes in a randomised placebo-controlled trial. Lancet 2010; 376: 886-894.

3. Kannel WB, Kannel C, Paffenbarger RS Jr, Cupples LA. Heart rate and cardiovascular mortality: The Framingham Study. Am Heart J 1987; 113: 1489-1494.

4. Greenland P, Daviglus ML, Dyer AR, Liu K, Huang CF, Goldberger JJ, et al. Resting heart rate is a risk factor for cardiovascular and noncardiovascular mortality: The Chicago Heart Association Detection Project in Industry. Am J Epidemiol 1999; 149: $853-862$.

5. Fox K, Ford I, Steg PG, Tendera M, Robertson M, Ferrari R. Heart rate as a prognostic risk factor in patients with coronary artery disease and left-ventricular systolic dysfunction (BEAUTIFUL): A subgroup analysis of a randomised controlled trial. Lancet 2008; 372: 817-821.

6. Shaper AG, Wannamethee G, Macfarlane PW, Walker M. Heart rate, ischaemic heart disease, and sudden cardiac death in middle-aged British men. Br Heart J 1993; 70: 49-55.

7. Bohm M, Cotton D, Foster L, Custodis F, Laufs U, Sacco R, et al. Impact of resting heart rate on mortality, disability and cognitive decline in patients after ischaemic stroke. Eur Heart $J$ 2012; 33: $2804-2812$.

8. Erdur H, Scheitz JF, Grittner U, Laufs U, Endres M, Nolte CH. Heart rate on admission independently predicts in-hospital mortality in acute ischemic stroke patients. Int J Cardiol 2014; 176: 206-210.

9. Nolte CH, Erdur H, Grittner U, Schneider A, Piper SK, Scheitz
JF, et al. Impact of heart rate on admission on mortality and morbidity in acute ischaemic stroke patients: Results from VISTA. Eur J Neurol 2016; 23: 1750-1756.

10. Fox K, Bousser MG, Amarenco P, Chamorro A, Fisher M, Ford I, et al. Heart rate is a prognostic risk factor for myocardial infarction: A post hoc analysis in the PERFORM (Prevention of cerebrovascular and cardiovascular Events of ischemic origin with teRutroban in patients with a history oF ischemic strOke or tRansient ischeMic attack) study population. Int J Cardiol 2013; 168: $3500-3505$.

11. Qiu M, Sato S, Zheng D, Wang X, Carcel C, Hirakawa Y, et al. Admission heart rate predicts poor outcomes in acute intracerebral hemorrhage: The intensive blood pressure reduction in acute cerebral hemorrhage trial studies. Stroke 2016; 47: 1479-1485.

12. Iwahana H, Ishikawa S, Ishikawa J, Kabutoya T, Kayaba K, Gotoh T, et al. Atrial fibrillation is a major risk factor for stroke, especially in women: The Jichi Medical School cohort study. $J$ Epidemiol 2011; 21: 95-101.

13. Wolf PA, Abbott RD, Kannel WB. Atrial fibrillation as an independent risk factor for stroke: The Framingham Study. Stroke 1991; 22: 983-988.

14. McGrath ER, Kapral MK, Fang J, Eikelboom JW, O'Conghaile A, Canavan M, et al. Association of atrial fibrillation with mortality and disability after ischemic stroke. Neurology 2013; 81: $825-832$.

15. Kongbunkiat K, Kasemsap N, Travanichakul S, Thepsuthammarat K, Tiamkao S, Sawanyawisuth K. Hospital mortality from atrial fibrillation associated with ischemic stroke: A national data report. Int J Neurosci 2015; 125: 924-928.

16. Li J, Becker R, Rauch B, Schiele R, Schneider S, Riemer T, et al. Usefulness of heart rate to predict one-year mortality in patients with atrial fibrillation and acute myocardial infarction (from the OMEGA trial). Am J Cardiol 2013; 111: 811-815.

17. Steinberg BA, Kim S, Thomas L, Fonarow GC, Gersh BJ, Holmqvist $F$, et al. Increased heart rate is associated with higher mortality in patients with atrial fibrillation (AF): Results from the Outcomes Registry for Better Informed Treatment of AF (ORBIT-AF). J Am Heart Assoc 2015; 4: E002031.

18. Hillis GS, Woodward M, Rodgers A, Chow CK, Li Q, Zoungas $\mathrm{S}$, et al. Resting heart rate and the risk of death and cardiovascular complications in patients with type 2 diabetes mellitus. Diabetologia 2012; 55: 1283-1290.

19. Chu CH, Weng WC, Su FC, Peng TI, Chien YY, Wu CL, et al. Association between atrial fibrillation and three-year mortality in nondiabetic patients with acute first-ever ischemic stroke. J Stroke Cerebrovasc Dis 2016; 25: 2660-2667.

20. Yaghi S, Sherzai A, Pilot M, Sherzai D, Elkind MS. The CHADS2 components are associated with stroke-related inhospital mortality in patients with atrial fibrillation. $J$ Stroke Cerebrovasc Dis 2015; 24: 2404-2407.

21. Van Gelder IC, Groenveld HF, Crijns HJ, Tuininga YS, Tijssen JG, Alings AM, et al. Lenient versus strict rate control in patients with atrial fibrillation. $N$ Engl J Med 2010; 362: 1363-1373.

22. Sander D, Winbeck K, Klingelhofer J, Etgen T, Conrad B. Prognostic relevance of pathological sympathetic activation after acute thromboembolic stroke. Neurology 2001; 57: 833-838.

23. Winklewski PJ, Radkowski M, Demkow U. Cross-talk between the inflammatory response, sympathetic activation and pulmonary infection in the ischemic stroke. J Neuroinflammation 2014; 11: 213 .

24. den Hertog HM, van Rossum JA, van der Worp HB, van Gemert $\mathrm{HM}$, de Jonge R, Koudstaal PJ, et al. C-reactive protein in the very early phase of acute ischemic stroke: Association with poor outcome and death. J Neurol 2009; 256: 2003-2008.

25. Katzan IL, Cebul RD, Husak SH, Dawson NV, Baker DW. The effect of pneumonia on mortality among patients hospitalized for acute stroke. Neurology 2003; 60: 620-625.

26. Yong M, Kaste M. Dynamic of hyperglycemia as a predictor of stroke outcome in the ECASS-II trial. Stroke 2008; 39: $2749-2755$.

27. Capes SE, Hunt D, Malmberg K, Pathak P, Gerstein HC. Stress hyperglycemia and prognosis of stroke in nondiabetic and diabetic patients: A systematic overview. Stroke 2001; 32: $2426-2432$

\section{Supplementary Files}

Please find supplementary file(s);

http://dx.doi.org/10.1253/circj.CJ-19-0946 